\title{
Risk factors for gastroesophageal reflux disease: the role of diet
}

\author{
Mirosław Jarosz, Anna Taraszewska \\ National Food and Nutrition Institute, Warsaw, Poland
}

Prz Gastroenterol 2014; 9 (5): 297-301

DOI: $10.5114 /$ pg.2014.46166

Key words: gastroesophageal reflux disease, dietary habits, risk factors.

Address for correspondence: Prof. Mirosław Jarosz PhD, National Food and Nutrition Institute, 61/63 Powsińska St, 02-903 Warsaw, Poland, phone: +48 2255096 77, e-mail: jarosz@izz.waw.pl

\begin{abstract}
Introduction: Nutrition can contribute to the development of gastroesophageal reflux disease (GERD). The relevant studies often provide contradictory results.

Aim: To determine GERD risk factors associated with dietary habits.

Material and methods: A total of 513 subjects were included. The study group consisted of adults with a recent clinically confirmed diagnosis of GERD, and the control group were healthy adults. The research tool was a proprietary questionnaire. Risk factors were evaluated by logistic regression models.

Results: An association was found between the severity of typical GERD symptoms and a certain diet $(p<0.001)$. The symptoms were experienced more often after fatty, fried, sour, or spicy food and sweets. The univariate logistic regression analysis showed the following risk factors: eating $1-2$ meals per day $(\mathrm{OR}=3.50,95 \% \mathrm{Cl}: 1.75-6.98)$, everyday consumption of peppermint tea $(\mathrm{OR}=2.00,95 \% \mathrm{Cl}: 1.14-3.50)$, and eating one, big meal in the evening instead of dinner and supper ( $\mathrm{OR}=1.80,95 \% \mathrm{Cl}: 1.05-3.11)$. The multivariate analysis confirmed that frequent peppermint tea consumption was a risk factor $(\mathrm{OR}=2.00,95 \% \mathrm{Cl}: 1.08-3.70)$.

Conclusions: Taking into consideration the results of this study, it seems that patients should be recommended to eat more than three meals a day and eat dinner and supper at appropriate times instead of one, big meal in the evening. The role of frequent peppermint tea consumption in GERD development requires further studies.
\end{abstract}

\section{Introduction}

Gastroesophageal reflux disease (GERD) is a chronic gastrointestinal disease that significantly reduces quality of life and, in some patients, leads to serious complications, such as oesophageal stricture, gastrointestinal bleeding, or Barrett's oesophagus. According to various sources, the typical symptoms of this disease (heartburn, discomfort in the upper abdomen, acid eructation) are experienced daily by $4-10 \%$, and weekly by $10-30 \%$ of the adult population in Western countries $[1,2]$. In Poland, GERD is diagnosed in $36 \%$ of patients visiting the doctor for abdominal complaints [3]. It is estimated that this disease will become more and more common. There are many factors that can contribute to the development of this disease, including lifestyle and nutrition, but relevant studies often provide contradictory results [4-6].

\section{Aim}

The aim of this study was to determine the risk factors for GERD associated with dietary habits.

\section{Material and methods}

The study was carried out in the years 2006-2011 and included patients referred for gastroscopy to the Mazowiecki Bródnowski Hospital, Warsaw. The study group (GERD group) were patients aged 18-65 years with symptoms of GERD (heartburn, acid eructation, sour-bitter taste in the mouth, pain in the upper abdomen and epigastric fullness after a meal, the sensation of a "lump in the throat", chest pain, recurrent cough, and hoarse voice), with gastroscopically confirmed non-erosive disease or oesophagitis (graded according to Los Angeles classification). The control group were healthy adults up to 65 years of age with no GERD symptoms or experiencing GERD symptoms very rarely, i.e. once a month or less. Excluded were patients outside the age range, with active peptic ulcer or neoplasms, pregnant women, and patients with incomplete inquiry information on dietary habits. A total of 513 subjects were enrolled. Data on the patients' usual diet were obtained with the use of a proprietary 
questionnaire form developed on the basis of literature sources and own observations. The study was approved by the Ethics Committee of the Food and Nutrition Institute.

\section{Statistical analysis}

Statistical analysis of the obtained data was performed using Statistica 10 software (StatSoft). For inter-group comparisons of distribution of variables the Pearson's $\chi^{2}$ test or Fisher's exact test was used. The threshold for significance was set at $p \leq 0.05$. The strength of relation between each variable and risk of GERD was evaluated by univariate and multivariate logistic regression model. Variables with odds ratio (OR) $>1$ and $p \leq 0.05$ were considered significant risk factors for GERD.

\section{Results}

The GERD group included 189 females (67\%) and 93 males (33\%). The average age of the subjects was $45.7 \pm 13.1$ years. Non-erosive disease was diagnosed in 215 patients $(76.2 \%)$ and oesophagitis was diagnosed in 67 patients $(23.8 \%)$. The average body mass index (BMI) in this group was $25.4 \mathrm{~kg} / \mathrm{m}^{2}$. The control group included 153 females (66.2\%) and 78 males (33.8\%). The average age of the subjects was $43.8 \pm 14.7$ years. The average BMI in this group was $24.4 \mathrm{~kg} / \mathrm{m}^{2}$.

The GERD patients reported a relationship between the severity of typical disease symptoms and eating certain foods, significantly more often than the control group ( $p<0.001)$. In the GERD group, the symptoms appeared more after consumption of products that are high in fat $(p=0.004)$, fried $(p=0.022)$, sour $(p=0.003)$, or spicy $(p=0.014)$, and after fruits $(p=0.001)$ and sweets $(p=0.011)$.

Patients in both groups usually had three meals a day. However, it was determined that in the study group the patients had only two meals a day significantly more often $(p<0.001)$, and four meals a day significantly less often $(p<0.001)$. Patients in both groups usually had breakfast, dinner, and supper. The GERD patients had lunch as an additional meal significantly less often $(p<0.001)$, and significantly more often $(p=0.03)$ they ate one big meal instead of dinner and supper. Patients in this group significantly more often $(p<0.001)$ had at least one big meal. The big meal was more often in the evening $(p<0.021)$, and less often at breakfast time $(p=0.003)$. The study groups could not be differentiated by regularity of meals, speed of eating, or eating between meals. Instead, the groups differed in frequency of having products/dishes described in the sources as refluxogenic, i.e. products/dishes high in fat, tomatoes and tomato products, alliums, chocolate products, hot spices, citrus fruits and juices, peppermint tea, coffee, carbonated beverages, and alcohol. Patients in the study group significantly more often had tomatoes and tomato products, chocolate and chocolate products, citrus fruits and juices $(p<0.001)$, as well as peppermint

Table I. Results of univariate and multivariate logistic regression analysis of risk factors for GERD

\begin{tabular}{|c|c|c|c|c|}
\hline Factor & OR & $(-) 95 \% \mathrm{Cl}$ & $(+) 95 \% \mathrm{Cl}$ & Value of $p$ \\
\hline \multicolumn{5}{|l|}{ Univariate logistic regression analysis: } \\
\hline Eating 1-2 meals a day & 3.50 & 1.75 & 6.98 & $<0.001$ \\
\hline Eating fatty products & 3.33 & 0.57 & 19.51 & 0.181 \\
\hline Eating sweets & 3.28 & 0.39 & 27.65 & 0.273 \\
\hline Eating spicy products & 3.14 & 0.48 & 20.62 & 0.231 \\
\hline Eating fried products & 2.59 & 0.82 & 8.13 & 0.103 \\
\hline Drinking peppermint infusion & 2.00 & 1.14 & 3.50 & 0.015 \\
\hline Eating one big meal in the evening & 1.80 & 1.05 & 3.11 & 0.034 \\
\hline Drinking fruit juices & 1.27 & 0.48 & 3.40 & 0.629 \\
\hline Eating sour products & 1.10 & 0.48 & 2.54 & 0.813 \\
\hline Eating fruits & 1.04 & 0.44 & 2.44 & 0.930 \\
\hline Drinking alcohol & 0.83 & 0.34 & 1.98 & 0.669 \\
\hline \multicolumn{5}{|l|}{ Multivariate logistic regression analysis: } \\
\hline Eating 1-2 meals a day & 2.01 & 0.86 & 4.67 & 0.104 \\
\hline Drinking peppermint infusion & 2.00 & 1.08 & 3.70 & 0.027 \\
\hline Eating one big meal in the evening & 1.59 & 0.79 & 3.20 & 0.195 \\
\hline
\end{tabular}

$O R$ - odds ratio, $\mathrm{Cl}$ - confidence interval 
infusion ( $p=0.015)$. In case of alliums and coffee, GERD patients more often admitted that they consumed these products once a week or did not consume them at all ( $p<0.001$ and $p=0.007$, respectively). As compared to the control group, alcohol was consumed by GERD patients significantly less often $(p<0.001)$, and carbonated beverages were not consumed at all.

Univariate logistic regression analysis showed that risk factors for GERD are as follows: eating 1-2 meals a day, drinking peppermint tea everyday, and eating one large meal in the evening. Multivariate logistic regression analysis confirmed that drinking peppermint tea everyday constituted a risk factor. The results of both analyses can be found in Table I.

\section{Discussion}

Gastroesophageal reflux disease is a chronic disease of multifactorial aetiology, where both environmental and genetic factors may play a role. Worldwide studies on various populations show that risk factors for GERD include age, excessive body mass, lifestyle factors (such as smoking, physical activity), and diet [4-6]. The role of diet as a risk factor for GERD has not been clarified yet and study results are contradictory.

It is commonly believed that certain eating habits, such as eating quickly and irregularly, eating big meals, eating between meals, or eating directly before sleep, may contribute to the appearance of the symptoms of this disease. However, several studies failed to confirm the influence of these habits on the occurrence/aggravation of the disease symptoms [7-10]. The present study showed no influence of regularity and speed of eating meals or eating between meals on the occurrence of GERD symptoms. However, an association was found between the low number of meals, i.e. 1-2 meals a day, and having the symptoms. Because there are no literature data on the number of meals a day eaten by the patients, we cannot compare this observation with other study results. However, according to general dietary principles, eating rarely is not a healthy habit and therefore it should be recommended, also to GERD patients, to eat more meals each day - minimum 3, and, optimally, 4 or 5 meals a day. It can be assumed that with 1-2 meals a day, each meal is larger. In this present study patients often had one large meal instead of dinner and supper, which could increase the occurrence of symptoms. This observation is in line with the biomechanical theory, according to which excessive (lasting many years) stretching of the stomach walls, e.g. due to big meals and air accumulating in the fundus of the stomach during eating, leads to weakening the mechanisms regulating the functions of lower oesophageal sphincter (LES) [11]. The association between large meals and heartburn has also been shown in papers by other authors [8, 12].

Literature sources most often list the following products as refluxogenic: products/dishes high in fat, spicy or sour, citrus fruits and juices, alliums, tomatoes and tomato juice, chocolate, coffee, beverages and products containing peppermint, carbonated beverages, and alcohol. These products cause or aggravate GERD symptoms by various mechanisms, e.g. decreasing tension of the LES, delaying stomach evacuation, stimulating sensory receptors in the oesophagus, or increasing gastric juice secretion [13-16]. In the present study, patients reported symptoms most often after consumption of the following products/dishes: fatty, fried, sour, or spicy food, fruits and sweets (mostly chocolate). Moreover, patients with GERD, more often than healthy subjects, ate tomatoes and tomato products, citrus fruits and juices, chocolate and chocolate products, and peppermint tea. Some of these products may have contributed to their complaints. Apparently, not only eating certain products, but also the frequency of eating them may play a role in causing/aggravating disease symptoms. This issue requires further research. The negative influence of some of the above-mentioned products was confirmed in a Korean study, where products such as alcohol, bakery products, carbonated beverages, and caffeine-containing products were also enumerated as refluxogenic [7]. A positive correlation between high fat intake and GERD symptoms was confirmed by the research of other authors [17, 18]. Fatty products/dishes decrease LES tension and delay stomach evacuation, which contributes to GERD symptoms [7, 8, 19-21]. Several studies failed to confirm the role of a diet high in fat in triggering the disease symptoms [15, 22-24]. Zheng et al., contrary to our study, did not confirm the influence of eating fried dishes and fruits on the occurrence and severity of GERD symptoms [5]. Sour or spicy food and sweets were denoted as causing the disease symptoms in a study by Śmiechowska and Cugowska [25]. These results were also confirmed by our study. Sour products, fruits and fruit juices - due to low $\mathrm{pH}$ - and spicy products/dishes - due to the presence of irritant alkaloids, such as capsaicin - stimulate mechanoreceptors in the oesophagus, which may cause unpleasant symptoms, especially if inflammatory lesions of the mucous membrane are present in the oesophagus $[14,16,26]$. Dore et al., in turn, did not confirm the association between chocolate products and the disease symptoms [9]. The present study showed that drinking peppermint infusion constitutes a risk factor for GERD. It seems, however, that this result should be interpreted with caution, because the fact that the patients had peppermint tea significantly more often 
might have been caused by their intent to alleviate stomach complaints and a lack of awareness that peppermint infusion may cause/intensify heartburn. Literature sources suggest that peppermint decreases LES tension; moreover, peppermint oil (studied in animal models) relaxes the smooth muscles of the alimentary tract $[27,28]$. Oliveria et al. found that $8 \%$ of heartburn patients reported complaints after consuming peppermint [18]. In contrast, Terry et al. and Bulat et al. did not observe any effect of consuming products and beverages with peppermint on reflux episodes $[26,29]$. This issue requires further research.

\section{Conclusions}

Taking into consideration the results of the present study pertaining to prevention of and diet therapy for GERD, it seems that patients should be recommended to eat at least 3 meals a day, preferably 4-5 meals a day, and eat dinner and supper at appropriate times instead of one, big meal in the evening. The role of frequent peppermint tea consumption in GERD development requires further studies. Nevertheless, it is advisable to inform the patients that peppermint infusion is not always a recommended method of soothing stomach complaints.

Taking into consideration the fact that study results regarding the influence of various dietary factors on the presence of the disease symptoms are often contradictory, it seems justified to develop individualised dietary recommendations for GERD patients to improve the effectiveness of diet therapy.

\section{Acknowledgments}

Financing of the study: statutory activity of the National Food and Nutrition Institute

\section{References}

1. El-SeragHB, Petersen NJ, Carter J, et al. Gastroesophageal reflux among different racial groups in the United States. Gastroenterology 2004; 126: 1692-9.

2. El-Serag H, Hill C, Jones R. Systematic review: the epidemiology of gastro-oesophageal reflux disease in primary care, using the UK General Practice Research Database. Aliment Pharmacol Ther 2008; 29: 470-80.

3. Ziółkowski BA, Pacholec A, Kudlicka M, et al. Prevalence of abdominal symptoms in the Polish population. Prz Gastroenetrol 2012; 7: 20-5.

4. Nilsson $M$, Johnsen $R$, Ye $W$, et al. Lifestyle related risk factors in the aetiology of gastro-oesophageal reflux. Gut 2004; 53 : 1730-5.

5. Zheng Z, Nordenstedt H, Pedersen NL, et al. Lifestyle factors and risk for symptomatic gastroesophageal reflux in monozygotic twins. Gastroenterology 2007; 132: 87-95.
6. Lee SJ, Jung MK, Kim SK, et al. Clinical characteristics of gastroesophageal reflux disease with esophageal injury in Korean: focusing on risk factors. Korean J Gastroenterol 2011; 57: 281-7.

7. Song JH, Chung SJ, Lee JH, et al. Relationship between gastroesophageal reflux symptoms and dietary factors in Korea. J Neurogastroenterol Motil 2011; 17: 54-60.

8. Iwakiri K, Kobayashi M, Kotoyori M, et al. Relationship between postprandial esophageal acid exposure and meal volume and fat content. Dig Dis Sci 1996; 41: 926-30.

9. Dore MP, Maragkoudakis E, Fraley K, et al. Diet, lifestyle and gender in gastro-esophageal reflux disease. Dig Dis Sci 2008; 53: 2027-32.

10. Orr WC, Harnish MJ. Sleep-related gastro-esophageal reflux: provocation with e late evening meal and treatment with acid suppression. Aliment Farmacol Ther 1998; 12: 1033-8.

11. Salvia G, De Vizia B, Manguso F, et al. Effect of intragastric volume and osmolality on mechanisms of gastroesophageal reflux in children with gastroesophageal reflux disease. Am J Gastroenterol 2001; 96: 1725-32.

12. Fujiwara Y, Machida A, Watanabe $Y$, et al. Association between dinner-to-bed time and gastroesophageal reflux disease. Am J Gastroenetrol 2005; 100: 2633-6.

13. Hampeel H, Abraham NS, El-Serag HB. Meta-analysis: obesity and the risk of gastroesophageal reflux disease and its complications. Ann Intern Med 2005; 143: 199-211.

14. Myklebust S, Espelid I, Svalestad S, et al. Dental health behavior, gastroesophageal disorders and dietary habits among Norwegian recriuts in 1990 and 1999. Acta Odontol Scand 2003; 61: 100-4.

15. Pehl C, Waizenhoefer A, Wendl B, et al. Effect of low and high fat meals on lower esophageal sphincter motility and gastroesophageal reflux in healthy subjects. Am J Gastroenterol 1999; 94: 1192-6.

16. Rodriguez-Stanley S, Collings KL, Robinson M, et al. The effects of capsaicin on reflux, gastric emptying and dyspepsia. Aliment Pharmacol Ther 2000; 14: 129-34.

17. Bolin TD, Korman MG, Hansky J, et al. Heartburn: community perceptions. J Gastroenterol Hepatol 2000; 15: 35-9.

18. Oliveria SA, Christos PJ, Talley NJ, et al. Heartburn risk factors, knowledge, and prevention strategies: a population-based survey of individuals with heartburn. Arch Intern Med 1999; 159: 1592-8.

19. El-Serag $\mathrm{H}$. The association between obesity and GERD: a review of the epidemiological evidence. Dig Dis Sci 2008; 53: 2307-12.

20. Shapiro M, Green C, Bautista JM, et al. Assessment of dietary nutrients that influence perception of intra-oesophageal reflux disease. Aliment Pharmacol Ther 2007; 25: 93-101.

21. Holloway RH, Lyrenas E, Ireland A, et al. Effect of intraduodenal fat on lower oesophageal sphincter function and gastro-oesophageal reflux. Gut 1997; 40: 449-53.

22. Nandurkar S, Locke GR 3rd, Fett S, et al. Relationsheep between body mass index, diet, exercise and gastro-esophageal reflux symptoms in a community. Aliment Pharmacol Ther 2004; 20: 497-505.

23. Ruhl CE, Everhart JE et al. Overweight, but not high dietary fat intake, increases risk of gastroesophageal reflux disease 
hospitalization: the NANHES I Epidemiologic Follow-up Study. First Nations Health and Nutrition Examination Survey. Ann Epidemiol 1999; 9: 424-35.

24. Colombo P, Mangano M, Bianchi PA, et al. Effect of calories and fat on postprandial gastro-oesophageal reflux. Scand J Gastroenterol 2002; 37: 3-5.

25. Śmiechowska M, Cugowska M. Rola żywności i żywienia w chorobie refleksowej [Polish]. Bromat Chem Toksykol 2011; 3: 298-304.

26. Terry P, Lagergren J, Wolk A, et al. Reflux-inducing dietary factors and risk of adenocarcinoma of the esophagus and gastric cardia. Nutr Cancer 2000; 38: 186-91.

27. Kahrilas PJ. GERD pathogenesis, pathophysiology and clinical manifestation. Cleveland Clin J Med 2003; 70: S4-19.

28. Hills JM, Aaronson PI. The mechanism of action of peppermint oil on gastrointestinal smooth muscle. An analysis using patch clamp electrophysiology and isolated tissue pharmacology in rabbit and guinea pig. Gastroenterology 1991; 101: 55-65.

29. Bulat R, Fachnie E, Chauhan U, et al. Lack of effect of spearmint on lower oesophageal sphincter function and acid reflux in healthy volunteers. Aliment Pharmacol Ther 1999; 13: 805-12.

Received: 20.01 .2014

Accepted: 1.05 .2014 